\title{
ZnO nanoparticles as solar photocatalysts: Synthesis, effect of annealing temperature and applications
}

\author{
S. Sathya ${ }^{1}$, J. Vijayapriya ${ }^{1}$, K. Parasuraman ${ }^{1}$, D. Benny Anburaj ${ }^{2}$, S. Joshua Gnanamuthu ${ }^{3 *}$ \\ ${ }^{1}$ PG and Research Department of Physics, Poompuhar College (Affiliated to Bharathidasan University), \\ Melaiyur, India \\ ${ }^{2}$ PG and Research Department of Physics, D. G. Govt. Arts College (Affiliated to Bharathidasan University), \\ Mayiladuthurai, India \\ ${ }^{3} \mathrm{PG}$ and Research Department of Physics, TBML College (Affiliated to Bharathidasan University), Porayar, India \\ *joshuagnanamuthu@gmail.com
}

DOI 10.17586/2220-8054-2020-11-6-672-679

\begin{abstract}
$\mathrm{ZnO}$ nanoparticles were prepared by a hydrothermal method from the source materials of Zinc acetylacetonate hydrate and ammonium hydroxide. Further prepared samples were annealed at various temperatures for 3 hours. X-ray diffraction analysiswas employed to study the structure and crystalline nature of synthesized nanoparticles. Scanning electron microscope images showed that the prepared $\mathrm{ZnO}$ nanoparticles acquired nano needle, hexagonal disk and porous nanorods structures due to the effect of annealing temperature. The photocatalytic activity of the prepared $\mathrm{ZnO}$ nanoparticles was evaluated for Methyl Blue (MB) dye which showed $94 \%$ of degradation and good stability for five cycles.
\end{abstract}

Keywords: $\mathrm{ZnO}$, hydrothermal, nanorods, photocatalysis, degradation.

Received: 13 August 2020

Revised: 30 August 2020

Final revision: 2 November 2020

\section{Introduction}

In recent years, the implementation of water reclamation and reuse is gaining attention rapidly world-wide due to the water scarcity occurred as a result of climate change and poor water resource management (i.e. limited access to clean water resources and water demands exceed the available resources). Access to clean water is becoming an ever increasing problem in an expanding global economy and population countries [1]. One of the attractive solutions in response to water issues is implementation of wastewater reclamation and reuse projects to ensure a sustainable water development and management.

POPs (Persistent Organic Pollutants) are carbon-based chemical substances that are resistant to environment degradation and have been continuously released into the environment. POPs can cause severe harm to human beings and wildlife because of their poor biodegradability and carcinogenic characteristics in nature. Advanced treatment technologies are crucial to ensure that the reclaimed water is free of POPs. Various water treatment techniques have been employed to remove POPs from water streams including adsorption, membrane separation and coagulation [2]; however, these processes only concentrate or change the recalcitrant organic pollutants from the water to solid phase. For this reason, advanced oxidation processes (AOPs) have been proposed for the elimination of recalcitrant organic pollutants, especially for those with low biodegradability.

AOPs offer several advantages such as: (i) rapid degradation rate, (ii) mineralization of organic compounds to green products, (iii) ability to operate under ambient temperature and pressure, and (iv) reduction of the toxicity of organic compounds.

Photocatalytic oxidation (PCO) technology has been active in the field of pollution control since the 1980s due to the sustained developments in the photocatalyzed degradation of aqueous pollutants. Photocatalytic oxidation method finds wide applications in photocatalytic degradation of aqueous pollutants due to its high efficiency, low cost, energy saving and production of no other secondary pollutants in this process. Over the past few decades broadband semiconducting photocatalysis attracted great interest of many workers because of the potential of the process to solve environmental problems $[3,4]$. These photocatalysis exhibit appropriate energy potential to conduct oxidation and reduction process on their semiconducting surface [5]. $\mathrm{ZnO}$ is one of the important II-VI groups of n-type semiconductors which has direct band gap of $3.37 \mathrm{eV}$ with large exciton binding energy of $60 \mathrm{meV}$. ZnO is proved to be a promising material for various applications, such as gas sensors [6], transistors [7], solar cells [8], hydrogen production [9] and photocatalysis [10] due to their electrical and optical properties.

Among the other semiconducting materials zinc oxide $(\mathrm{ZnO})$ is extensively studied due to their unique physicochemical, piezoelectric, optical and catalytic properties $[11,12]$. These properties are correlated with shape, size and 
morphology of $\mathrm{ZnO}$ nanoparticles [13, 14]. Santhosh et al. [15] reported that there are various proposed mechanisms for the degradation of dyes using the photocatalyst materials. One mechanism suggests that the oxidation of organic pollutants is first initiated by the free radicals, which are mainly induced by the electron-hole (e-/h+) pairs at the photocatalyst surface. Another mechanism states that the organic compound is firstly adsorbed on the photocatalyst surface and then reacts with excited superficial e-/h+ pair or $\mathrm{OH}$ radicals to form the final products. Hence, the photocatalytic performance of nanoparticles is determined by their shape and dimension. In recent years, investigation on the shape control synthesis of semiconducting nanostructures were carried out by many workers on $\mathrm{ZnO}$ nanostructures which lead to the formation of nanowires [16], nanotubes [17], nanobelts [18] and nanodisks [19] structures. ZnO nanostructures with different shapes and dimensions were developed by solution phase method such as sonochemical route [20,21], sol-gel method [22,23], reflux method [24] and hydrothermal method [25,26]. Controlling the shape of the $\mathrm{ZnO}$ nanostructures and fast synthetic route under the ambient condition have become an important topic of investigation in the field of materials chemistry. In the present work, the effect of temperature on the structural, optical and morphological properties of $\mathrm{ZnO}$ nanoparticles prepared by hydrothermal method is presented and the photocatalytic activity of the synthesized $\mathrm{ZnO}$ nanoparticles is analyzed against Methyl Blue dye.

\section{Materials and methods}

\subsection{Synthesis method}

$\mathrm{ZnO}$ nanopowders were synthesized by simple hydrothermal method using the aqueous solution of Zinc acetylacetonate hydrate $\left(\mathrm{Zn}(\mathrm{acac})_{2} \cdot \mathrm{H}_{2} \mathrm{O}\right)$ and $\mathrm{NH}_{4} \mathrm{OH}$. In a typical synthesis process, $1.3631 \mathrm{~g}$ of $\left(\mathrm{Zn}(\mathrm{acac})_{2}\right)$ was dissolved in $100 \mathrm{ml}$ of distilled water and $\mathrm{NH}_{4} \mathrm{OH}$ was added dropwise to maintain the $\mathrm{pH}$ of solution 7 under constant stirring. Then this solution was continuously stirred for 1 our and the resultant solution was transferred to Teflon-lined stainless steel autoclave of $100 \mathrm{ml}$ volume and maintained at $150{ }^{\circ} \mathrm{C}$ for 3 hours in muffle furnace. After the hydrothermal reaction the autoclave was naturally allowed to cool to room temperature. The product of white precipitate was obtained and washed with distilled water and ethanol several times and dried at hot air oven at $60{ }^{\circ} \mathrm{C}$. The dried particles were annealed at $300{ }^{\circ} \mathrm{C}$ for 3 hours. Similarly $\mathrm{ZnO}$ nanoparticles were prepared by hydrothermal method keeping the above experimental condition the same but the annealing temperature of the prepared dried particles was varying 400 , 500 and $600{ }^{\circ} \mathrm{C}$. The prepared $\mathrm{ZnO}$ nanoparticles were characterized for their structural, optical, and morphological properties and photocatalytic activities.

\subsection{Characterization}

Synthesized $\mathrm{ZnO}$ nanoparticles crystalline nature was analyzed by X-ray diffraction technique (PANalytical'sX'Pert Pro with $\mathrm{CuK} \alpha$ radiation). Field Emission Scanning Electron Microscopy and Energy Dispersive X-ray Spectroscopy (FEI Quanta FEG200) were employed to analyze the surface morphology and elemental composition of synthesized samples. Shimadzu, UV-2600 spectrophotometer is used to measure the optical transmittance of the samples at wavelengths ranging from $300-1100 \mathrm{~nm}$.

\section{Results and discussion}

\subsection{XRD analysis}

$\mathrm{X}$-ray diffraction (XRD) pattern of synthesized $\mathrm{ZnO}$ nanoparticles are shown in Fig. 1 which confirm the formation of ZnO wurtzite (hexagonal)structure when compared with the corresponding peaks of JCPDS card no. 70-2205. One can observe that the intensity of the XRD peaks of $\mathrm{ZnO}$ particles prepared samples is relatively high. Further, the intensity of XRD peak of (101) plane is relatively stronger in all the samples. The average crystallite size $(D)$ of the synthesized $\mathrm{ZnO}$ nanoparticles was calculated from Debye-Scherrer formula from (101) plane:

$$
D=\frac{K \lambda}{\beta \cos \theta} .
$$

The interplanar distance $(d)$ was calculated from Bragg's equation:

$$
2 d \sin \theta=n,
$$

where $\theta$ is the angle of diffraction in degree, $n=1$ and $\lambda$ is wavelength of X-rays used (1.5406 $\AA$ ). Lattice cell parameters $a(=b) A=\pi r^{2}$ and $c$ were calculated from the relation:

$$
\frac{1}{d^{2}}=\left\{\frac{4}{3}\left(\frac{h^{2}+h k+a^{2}}{a^{2}}\right)+\frac{l^{2}}{c^{2}}\right\},
$$




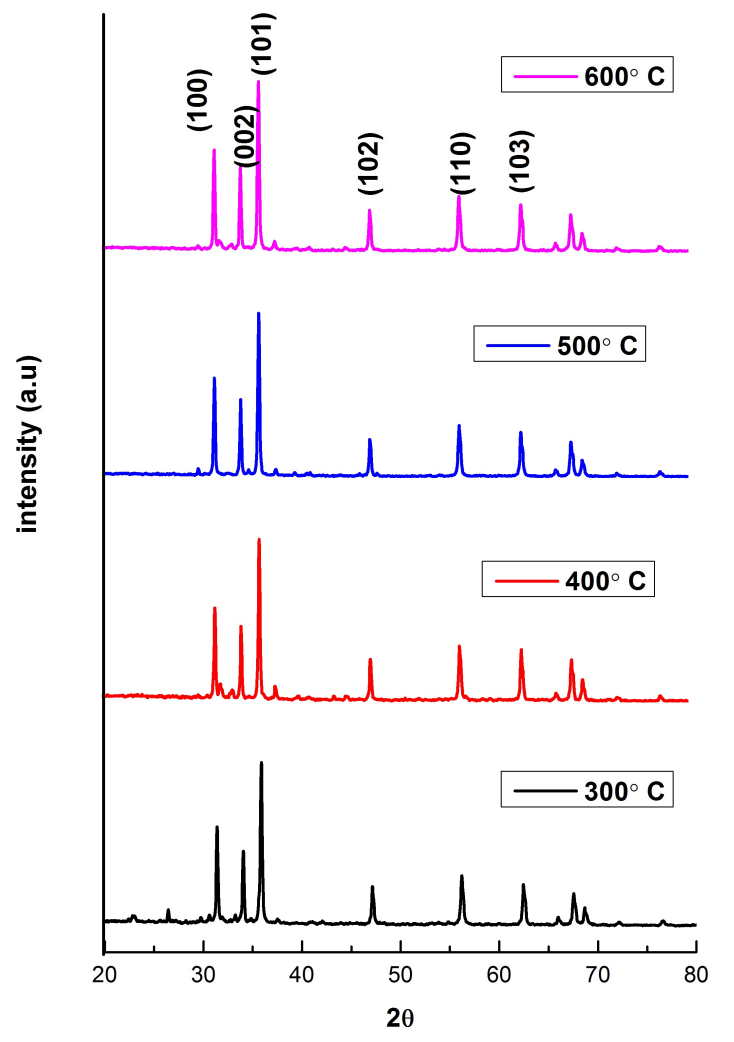

FIG. 1. XRD pattern of different annealed temperature $\mathrm{ZnO}$

where $d$ is the interplanar distance and $h, k$ and $l$ are Miller indices of the plane. The average crystallite size of (101) plane was decreased from 46.01 to $33.85,31.98$ and $31.10 \mathrm{~nm}$ with increase in annealed temperature from 300 , 400, 500 and $600{ }^{\circ} \mathrm{C}$ respectively. The calculated values are shown in Table 1.

TABLE 1. Variation of crystallite size and cell parameter of $\mathrm{ZnO}$ with different annealing temperatures

\begin{tabular}{|c|c|c|c|c|c|}
\hline \multirow{2}{*}{ Temp ${ }^{\circ} \mathrm{C}$} & \multicolumn{3}{|c|}{$(101)$ Plane } & \multicolumn{2}{c|}{ Cell parameters $(\AA)$} \\
\cline { 2 - 6 } & $2 \theta$ degree & $\begin{array}{c}\text { Average crystallite } \\
\text { size } D(\mathrm{~nm})\end{array}$ & $\begin{array}{c}\text { Inter planner } \\
\text { distance } d(\mathrm{~nm})\end{array}$ & $a=b$ & $c$ \\
\hline \hline 300 & 36.26 & 46.0 & 2.476 & 3.2521 & 5.2080 \\
\hline 400 & 36.26 & 33.8 & 2.476 & 3.2513 & 5.2065 \\
\hline 500 & 36.35 & 31.1 & 2.470 & 3.2403 & 5.1963 \\
\hline 600 & 36.36 & 31.9 & 2.471 & 3.2423 & 5.1963 \\
\hline
\end{tabular}

\subsection{SEM analysis}

Details on the growth factors controlling the shape and size of $\mathrm{ZnO}$ nanostructures are presented in Fig. 2, which shows the various morphology and shape selective synthesis of $\mathrm{ZnO}$ such as spindle like structure, hexagonal disks, spheroidal structures,and elongated porous hexagonal nanorods structure. Fig. 2 presents the hexagonal structure which shows the growth of $\mathrm{ZnO}$ nanorods obtained at $300{ }^{\circ} \mathrm{C}$. Further increasing the temperature is suppressed the growth and the formed hexagonal shaped nanodisks. Nanorods with porous structure are formed in $500{ }^{\circ} \mathrm{C}$.

Energy dispersive X-ray analyses (EDAX) spectrum of the prepared nanoparticle at $300,400,500$ and $600{ }^{\circ} \mathrm{C}$ are shown in Fig. 3(a-d) respectively, which reveal the presence of $\mathrm{Zn}$ and $\mathrm{O}$. 

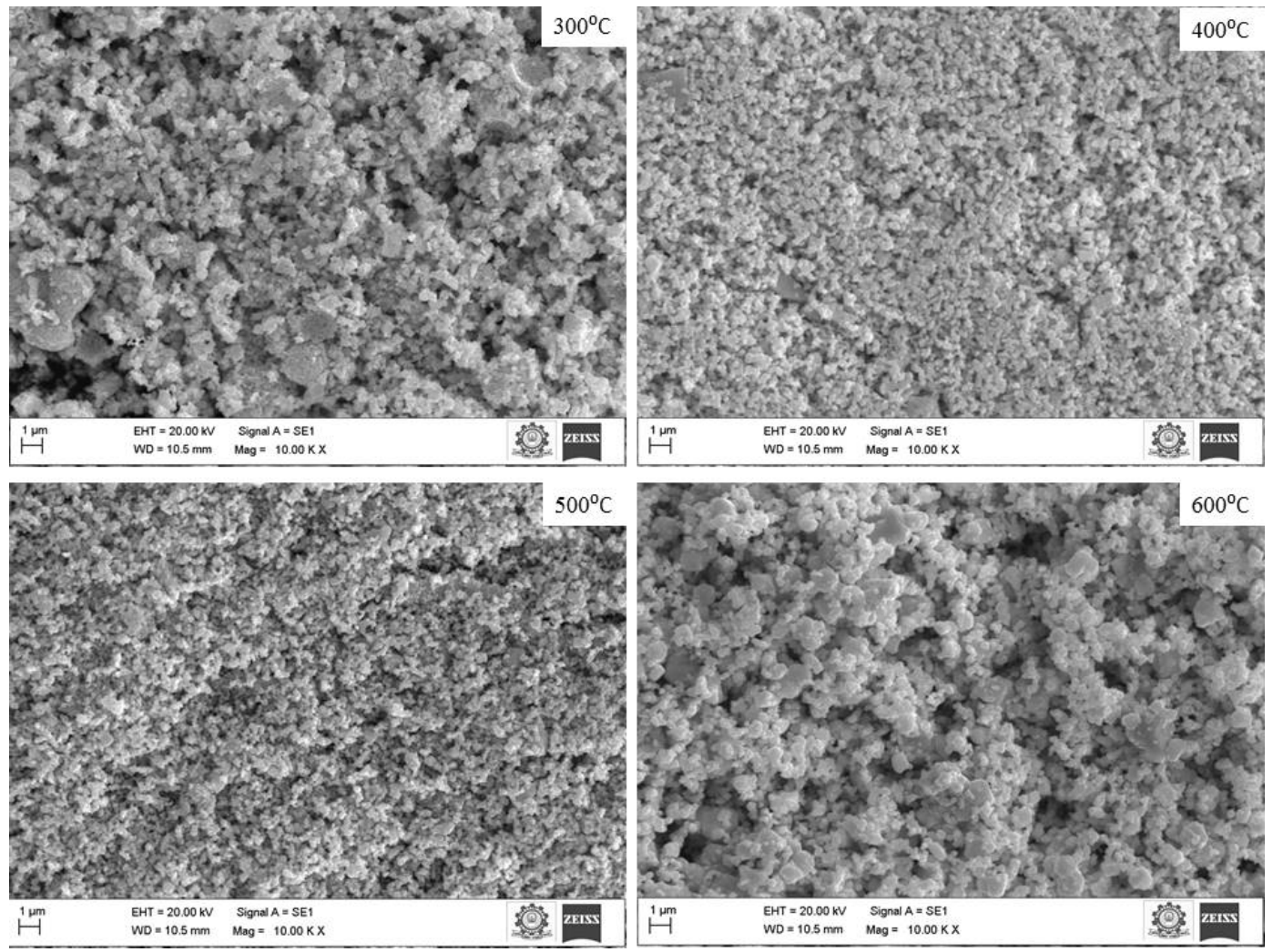

FIG. 2. SEM Images of $\mathrm{ZnO}$ particles
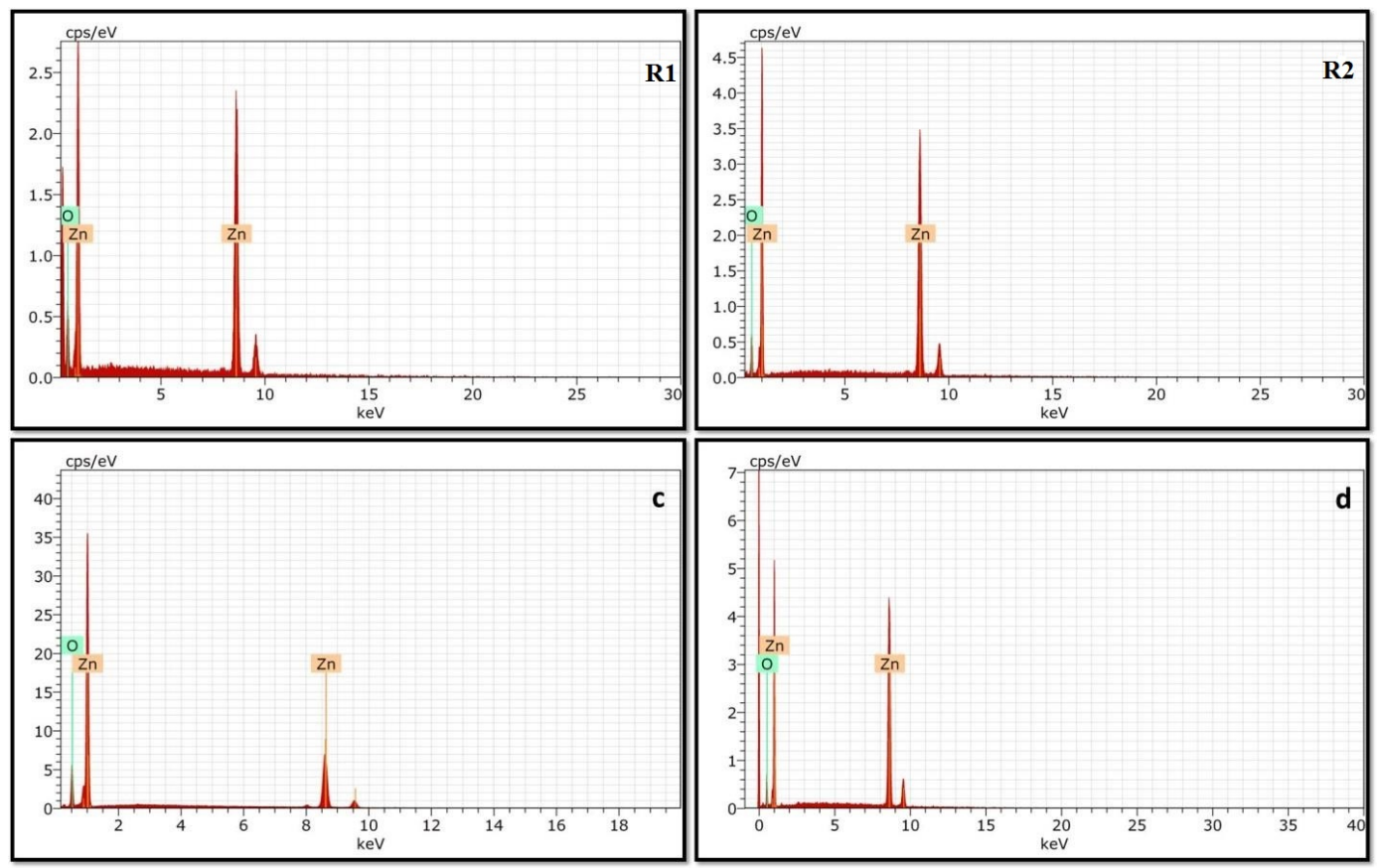

FIG. 3. EDAX analysis 


\subsection{Application of catalytic activity}

The photocatalytic degradation of methylene blue by the prepared photocatalyst of $\mathrm{ZnO} / \mathrm{UV}$ was studied under sun light. In this experiment, $\mathrm{ZnO}$ weight $(10 \mathrm{mg})$ were dispersed well in $(100 \mathrm{ml})$ aqueous methylene blue solution under stirring for (15 min) under dark conditions in order to make certain adsorption equilibrium on the surface of the catalysts.

After every $20 \mathrm{~min}$ of irradiation, part of the solution was collected and sealed in separate containers. They were centrifuged to separate the catalysts from the MB solution and then their UV-Vis spectra were recorded. Then absorption spectra were recorded and the rate of decolorization was observed in terms of change in intensity at $\lambda_{\text {max }}$ of the dyes. The efficiency of photocatalytic reaction was calculated from the following expression:

$$
D \%=\frac{A_{0}-A}{A_{0}} \times 100
$$

where $A_{0}$ the initial dye absorbance $\left(\mathrm{gm} \cdot \mathrm{L}^{-1}\right)$ and $A$ is the dye absorbance after the treatment. It can be noted that $A_{0}-A$ is referred to the loosing in the absorbance of solution by degradation process.

\subsection{The photocatalytic degradation of the Methyl Blue (MB)}

3.4.1. Effect of catalyst loading under sunlight. A series ofexperiments was carried out to assess the optimum catalystloading by the amount of catalyst $0.5 \mathrm{~g}$ of which the dye solution was prepared. The percent ages of photodegradation under sunlight at $48{ }^{\circ} \mathrm{C}$ with $\mathrm{ZnO}$ were illustrated in Fig. 4 . It was found that all samples give almost the same percentage removal at a certain concentration, so we will discuss here only prepared nanoparticle at $500{ }^{\circ} \mathrm{C}$. It was observed that with an increased catalyst amount, the photodegradation increases. This could be attributed to the fact that the number of active sites increased as the amount of the catalyst increased, up to a certain point, after which, the higher concentrations of the catalyst increase the turbidity of the MB suspension and the penetration of sunlight.

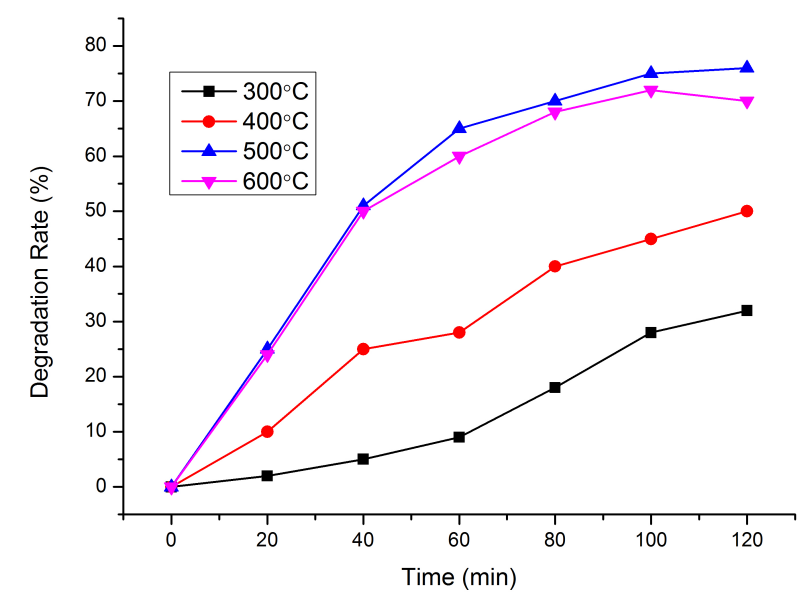

FIG. 4. Degradation efficiency graph

3.4.2. Photodegradation properties. To study the photodegradation abilities of the undoped $\mathrm{ZnO}$ particles prepared at various temperatures i.e. $300,400,500$ and $600{ }^{\circ} \mathrm{C}$; methyl blue (MB) dye was used as the model pollutant. The photocatalytic activity was performed by dispersing the films in $10 \mathrm{~mL}$ aqueous solution containing $0.1 \mathrm{M} \mathrm{MB}$ dye. After achieving adsorption-desorption equilibrium by stirring the dye solution with the catalysts in dark, they were exposed to visible light. With an increase in irradiation time, the color of the dye solutions degraded drastically. The order of the degradation ability after 120 min was as follows:

$$
300{ }^{\circ} \mathrm{C} \rightarrow 400{ }^{\circ} \mathrm{C} \rightarrow 600{ }^{\circ} \mathrm{C} \rightarrow 500{ }^{\circ} \mathrm{C} .
$$

A complete clear solution was observed for the co-doped sample confirming its enhanced degradation ability. The absorbance spectra taken at $\lambda=650 \mathrm{~nm}$ are displayed in Fig. 5(a) for the $300{ }^{\circ} \mathrm{C} \mathrm{ZnO}$, Fig. 5(b) for the $400{ }^{\circ} \mathrm{C}$, Fig. 5(c) for the $500{ }^{\circ} \mathrm{C}$ and Fig. 5(d) for the $600{ }^{\circ} \mathrm{C} \mathrm{ZnO}$ photocatalysts. 

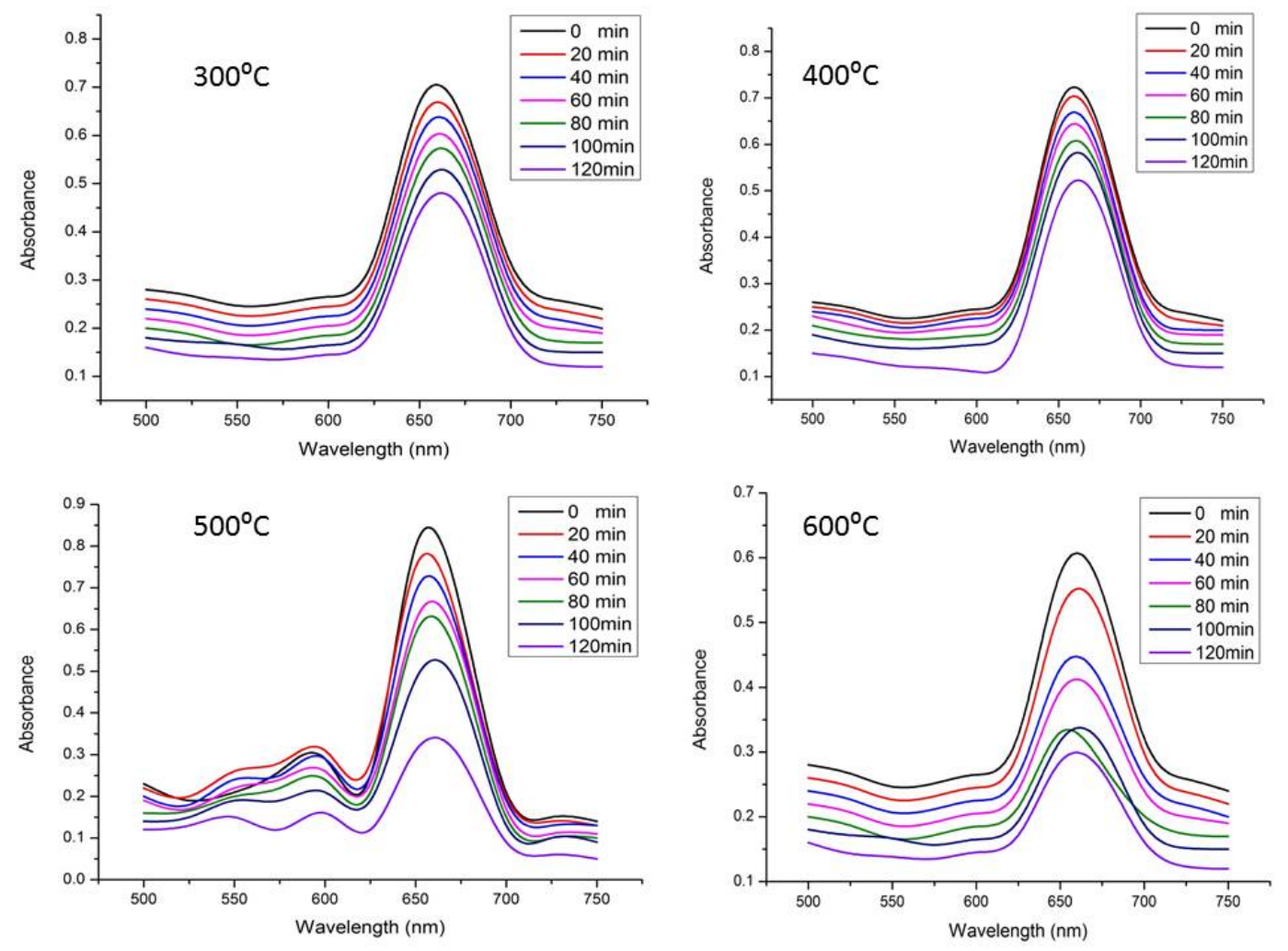

FIG. 5. Photocatalytic activity

Using the formula, $\eta=\left(1-C / C_{0}\right) \times 100$, (where $C$ and $C_{0}$ represents the dye concentration under light and dark conditions), the degradation efficiency values of the tested catalysts were calculated and depicted in Fig. 6. Unanimously, for all the irradiation time intervals, the $500{ }^{\circ} \mathrm{C} \mathrm{ZnO}$ photocatalyst showed better degradation efficiency.

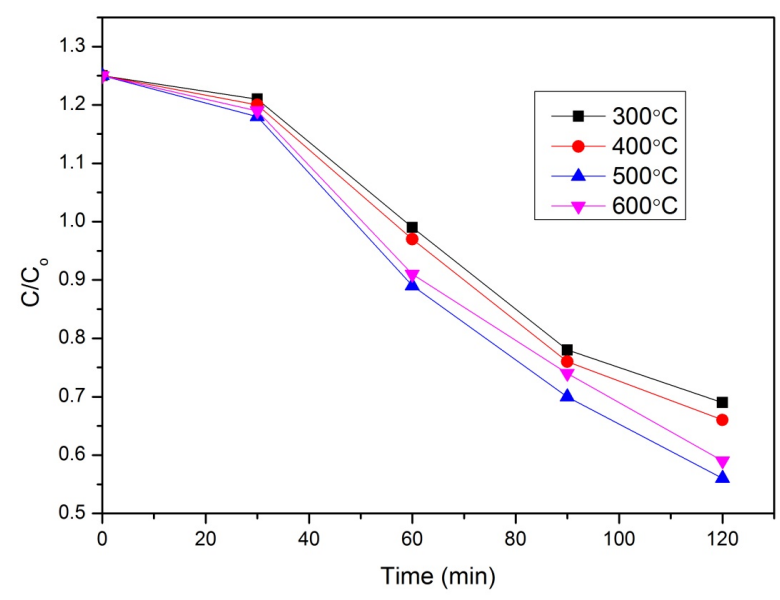

FIG. 6. $C / C_{0}$ vs time

In general, the photocatalytic efficiency of the catalyst could be decreased because of the following possible reason. (a) The continuous adsorption of dyes on the catalyst surface can reduce the active sites of the catalyst and thereby decreases the photocatalytic activity. In addition, the surface adsorbed dye can decrease the incident light penetration to the catalyst surface and it affects the electron-hole pair generation. 
To verify the reusable nature of the $\mathrm{ZnO}$ photocatalyst and durability of its catalytic activity in photodegradation process, 5 successive recycle tests were conducted by removing the catalyst from the dye solution. No significant loss was observed up to the first 4 cycles and a modest loss is observed in the 5th cycle (Fig. 7).

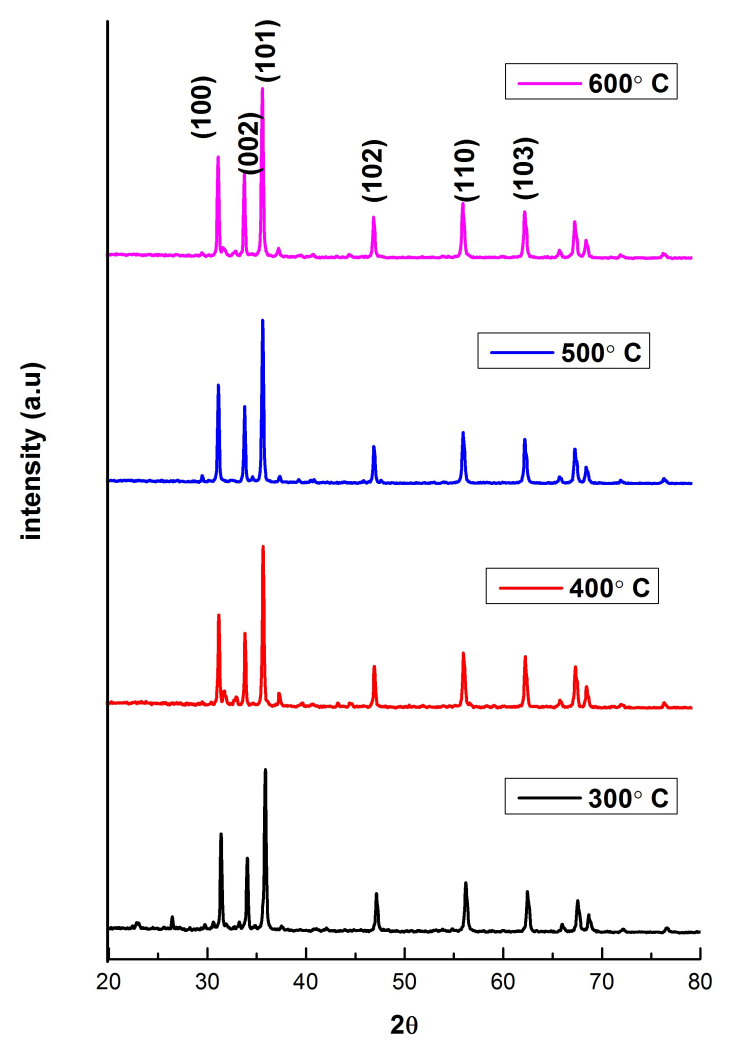

FIG. 7. Recycle test of the reused $\mathrm{ZnO}$ photocatalyst

\section{Conclusion}

In this work spindle like, hexagonal disk, porous nanorods structures are successfully obtained through a simple hydrothermal method by varying the annealing temperature of the $\mathrm{ZnO}$ particles. The SEM images show that the porous like nano structures in all the samples the increased porosity was observed in sample prepared at $500{ }^{\circ} \mathrm{C}$. $\mathrm{ZnO}$ nanoparticles possessing needle shaped structure showed $94 \%$ photocatalytic activity at about 120 min against MB dye. The $500{ }^{\circ} \mathrm{C}$ hydrothermal synthesized $\mathrm{ZnO}$ nanoparticles showed relatively high degradation of $\mathrm{MB}$.

\section{References}

[1] Hartley T.W. Public perception and participation in water reuse. Desalination, 2006, 187, P. 115-26.

[2] Plumlee M.H, Larabee J., Reinhard M. Peruorochemicals in water reuse. Chemosphere, 2008, 72, P. $1541-1547$.

[3] Peiyan Ma, Yan Wu, Zhengyi Fu, Weimin Wang. Shape-controlled synthesis and photocatalytic properties of three-dimensional and porous zinc oxide. J. Alloys Compd., 2011, 509, P. 3576-3581.

[4] Qazi Inamur Rahman, Musheer Ahmad, Sunil Kumar Misra, Minaxi Lohani. Effective photocatalytic degradation of rhodamine B dye by ZnO nanoparticles. Mater. Lett., 2013, 91, P. 170-174.

[5] Perera S.D., Mariano R.G., et al. Hydrothermal Synthesis of Graphene- $\mathrm{TiO}_{2}$ Nanotube Composites with Enhanced Photocatalytic Activity. ACS Catal., 2012, 2, P. 949-956.

[6] Rajesh Kumar, O. Al-Dossary, Girish Kumar, Ahmad Umar. Zinc Oxide Nanostructures for NO $\mathrm{N}_{2}$ GasSensor Applications: A Review. NanoMicro Lett., 2015, 7, P. 97-120.

[7] Hoffman R.L. ZnO-based transparent thin-film transistors. Appl. Phys. Lett., 2003, 82, P. 733-735.

[8] Jia Huang, Zhigang Yin, Qingdong Zheng. Applications of ZnO in organic and hybrid solar cells. Energy Environ. Sci., 2011, 4, P. 3861-3877.

[9] Steinfeld A. Solar hydrogen production via a two-step water-splitting thermochemical cycle based on $\mathrm{Zn} / \mathrm{ZnO}$ redox reactions. Int. J. Hydrogen Energy, 2002, 27, P. 611-619. 
[10] Eue Soon Jang, Jung-Hee Won, Seong-Ju Hwang, Jin-Ho Choy. Fine Tuning of the Face Orientation of ZnO Crystals to Optimize their Photocatalytic Activity. Adv. Mater, 2006, 18, P. 3309-3312.

[11] Zhong Lin Wang. ZnO nanowire and nanobelt platform for nano technology. Mater. Sci. Eng. R, 2009, 64, P. 33-71.

[12] Hongqiang Wang, Guanghai Li, et al. Controllable Preferential-Etching Synthesis and Photocatalytic Activity of Porous ZnO Nanotubes. J. Phys. Chem. C, 2008, 112, P. 11738-11743.

[13] Qingzhi Wu, Xia Chen, et al. Amino Acid-Assisted Synthesis of ZnO Hierarchical Architectures and Their Novel Photocatalytic Activities. Cryst. Growth Des., 2008, 8, P. 3010-3018.

[14] Xingfu Zhou, Dangyu Zhang, et al. Mechanistic Investigations of PEG-Directed Assembly of One-Dimensional ZnO Nanostructures. J. Phys. Chem. B, 2006, 110, P. 25734-25739.

[15] Santhosh C., Velmurugan V., et al. Role of nanomaterials in water treatment applications. Chem. Eng. J., 2016, 306, P. 1116-1137.

[16] Kong Y.C., Yu D.P., et al. Ultraviolet-emitting ZnO nanowires synthesized by a physical vapor deposition approach. Appl. Phys. Lett., 2001, 78, P. 406-409.

[17] Zhang B.P., Binh N.T., et al. Formation of highly aligned ZnO tubes on sapphire (0001) substrates. Appl. Phys. Lett., 2004, 84, P. 4098-4100.

[18] Zheng Wei Pan, Zu Rong Dai, Zhong Lin Wan. Nanobelts of Semiconducting Oxides. Science, 2001, 291, P. $1947-1949$.

[19] Xu C.X., Sun X.W., Dong Z.L., Yu M.B. Zinc oxide nanodisk. Appl. Phys. Lett., 2004, 85, P. 3878-3880.

[20] Seung-Ho Jung, Eugene Oh, et al. Sonochemical Preparation of Shape-Selective ZnO Nanostructures. Cryst. Growth Des., 2008,8 , P. $265-269$.

[21] Yadav R.S., Priya Mishra, Pandey A.C. Growth mechanism and optical property of ZnO nanoparticles synthesized by sonochemical method. Ultrasonics Sonochemistry, 2008, 15, P. 863-868.

[22] Khizar Hayat, Gondal M.A., et al. Nano ZnO synthesis by modified sol gel method and its application in heterogeneous photocatalytic removal of phenol from water. Appl. Catal. A: General, 2011, 393, P. 122-129.

[23] Seema Rani, Poonam Suri, Shishodia P.K., Mehra R.M. Synthesis of nanocrystalline ZnO powder via solgel route for dye-sensitized solar cells. Sol. Energy Mater. Sol. Cells, 2008, 92, P. 1639-1645.

[24] Jaykrushna Das, Deepa Khushalani. Nonhydrolytic Route for Synthesis of ZnO and Its Use as a Recyclable Photocatalyst. J. Phys. Chem. C, 2010, 114, P. 2544-2550.

[25] Matt Law, Greene L.E., et al. Nanowire dye-sensitized solar cells. Nat. Mater., 2005, 4, P. 445-459.

[26] Wang B.G., Shi E.W., Zhong W.Z. Twinning Morphologies and Mechanisms of ZnO Crystallites under Hydrothermal Conditions. Cryst. Res. Technol., 1998, 33, P. 937-941. 